DOI: $10.17805 /$ trudy.2020.1.8

\title{
МЕТОДЫ ФОРМИРОВАНИЯ И РЕАЛИЗАЦИИ МАРКЕТИНГОВЫХ КОММУНИКАЦИОННЫХ СТРАТЕГИЙ
}

\author{
Ю. В. Романюк \\ Московский гуманитарный университет
}

Аннотация: В статье рассмотрено понятие маркетинговых коммуникационных стратегий. Обозначены стратегии построения интегрированных маркетинговых коммуникаций.

Ключевые слова: маркетинговые коммуникации; реклама; Интернет

\section{METHODS OF FORMATION AND IMPLEMENTATION OF MARKETING COMMUNICATION STRATEGIES}

\author{
Yu. V. Romanyuk \\ Moscow University for the Humanities
}

Abstract: The article considers the concept of marketing communication strategies. The strategies for building integrated marketing communications are outlined.

Keywords: marketing communications; advertising; Internet

В сегодняшнем мире компании управляют сложной системой маркетинговых коммуникаций. Коммуникативная политика в деятельности современной организации направлена, прежде всего, на планирование и взаимодействие с широким кругом субъектов маркетинговой системы.

Зарубежные исследователи в области маркетинга Дж. Барнетта и С. Мориарти, считают, что маркетинговые коммуникации представляют собой процесс передачи и информации о товаре целевой аудитории (Бернет, Мориарти, 2015). В свою очередь, Ф. Котлер и К. Л. Келлер под маркетинговыми коммуникациями понимают «средства, с помощью которых фирмы пытаются информировать, убеждать и напоминать потребителям, о своих товарах и торговых марках» (цит. по: Таран, Воблая, 2017: 2561).

В. В. Зундэ дает более расширенное толкование анализируемого понятия: «Маркетинговые коммуникации в современном экономическом пространстве представляют собой систему инструментов, приемов и технологий, обеспечивающих формирование и передачу сигналов и сообщений рыночных субъектов о продвигаемых ими идеях, товарах или услугах целе- 
Научные труды Московского гуманитарного университета 2020 № 1

вым аудиториям и улавливание ответной реакции на них последних» (Зундэ, 2009: 38).

Как справедливо отмечает А. В. Короткова, «маркетинговые коммуникации представляют собой совокупность сигналов, исходящих от предприятий в адрес различных аудиторий. Содержит такие виды маркетинговой деятельности, как продвижение и public relations» (Коротков, 2019: 24).

Основные цели маркетинговых коммуникаций включают: информирование о продукции и ее свойствах; преодоление предрассудков; убеждение в преимуществах продукта; понимание продукта; создание мотивации для потребления и уверенность в качестве, надежности и других свойствах продукта; поддержание его имиджа.

Особое место в маркетинговых коммуникациях отводится стратегии. В теории менеджмента разные ученые дают различные описания сущности маркетинговой стратегии. Согласно подходу Л. Фридмана, маркетинговая стратегия - это фундаментальный элемент функционирования каждой компании, в котором сочетаются маркетинговые цели, создание ценности для всех заинтересованных сторон (клиентов, акционеров, поставщиков и т. д.), модификация стратегического управления в соответствии с быстроменяющейся рыночной средой, заимствование и внедрение опыта конкурентов, в том числе зарубежного (Фридман, 2018: 61). Кроме того, маркетинговая стратегия направлена на повышение интереса клиентов к предложениям компании и формирование конкурентного преимущества. Также, важной задачей является повышение удовлетворенности клиентов и, как следствие, лояльности (Симакина, 2019: 38).

Поэтому, для создания и удержания конкурентных преимуществ, корпоративные усилия менеджмента российских организаций, должны быть в первую очередь направлены на разработку коммуникационных стратегий маркетинга. Е. А. Лашкевич маркетинговую коммуникационную стратегию рассматривает как один из инструментов эффективного управления для достижения целей организации посредством применения позиционирования и комплекса маркетинга (Лашкевич, 2007: 53). В свою очередь И. М. Рубанова, под маркетинговой коммуникационной стратегией понимает согласование коммуникационных возможностей организации с ситуацией на рынке и с учетом применения различных каналов продвижения (Рубанова, Фалина, Дьяконова, 2012: 264). М. А. Кравец включает в понятие маркетинговой коммуникационной стратегии выбранные для достижения цели принципы и типы коммуникации; долгосрочный коммуникативный план, интегрированный с общей стратегией фирмы (Кравец, 2013: 150).

Таким образом, маркетинговая коммуникационная стратегия представляет собой комплексное воздействие на внутреннюю и внешнюю среду и включает весь комплекс мероприятий по продвижению информации о товаре или услуге. Объединение различных видов коммуникаций позволя- 
ет получить эффект синергии, позволяя добиваться большего результата, чем при их раздельном использовании. Поэтому, при реализации маркетинговой коммуникационной стратегии часто стали использовать интегрированные маркетинговые коммуникаций (ИМК). Некоторые исследователи определяют интегрированные маркетинговые коммуникации как, процесс развития и внедрения различных видов убеждающих коммуникативных программ, направленных на клиентов и, с течением времени, потенциальных клиентов (Симакина, 2019). Например, комплекс инструментов коммуникационной стратегии развития включает рекламу, выставки, персональные продажи, стимулирование сбыта, связи с общественностью, спонсирование различных мероприятий и т. д. Коммуникации в этом случае взаимодополняют друг друга. Возникает эффект синергии, который превышает эффективность действия суммы отдельных коммуникаций.

Стратегия построения интегрированных маркетинговых коммуникаций основывается на определённых принципах: интеграция выбора (сочетание различных средств коммуникаций); интеграция позиционирования (сочетание видов коммуникаций должно строится на синергическом взаимодействии); интеграция плана-графика.

Традиционно инструменты маркетинговых коммуникаций принято разделять на ATL («above-the-line») и BTL («below-the-line»).

ATL является прямой рекламой в традиционных средствах массовой информации, ориентированной на широкие группы общественности. Среди особенностей следует отметить, что технологии ATL оказывают сильное влияние на потребителей и являются обезличенными. При этом, данный вид рекламы являет наиболее затратным для организации, поэтому позволить себе ее могут только крупные компании.

Под BTL подразумевают рекламную технологию, использующую менее интенсивные/убеждающие методы, чем традиционная реклама (ATL), к которой относят директ-маркетинг (прямой маркетинг, направленный маркетинг) и стимулирование сбыта (продвижение продаж) (Павлова, Ярмухаметова, Зотова, 2015: 314).

Анализ информации позволил нам сгруппировать и выделить основные составляющие концепции ATL и BTL, что отражено на рис 1.

Следует отметить, что сегодня деление инструментов маркетинговых коммуникаций на ATL и BTL постепенно отходит на задний второй план, актуальным становится использование так называемых TTL («through-theline») инструментов, которые объединяют как ATL, так и BTL инструменты с целью получения максимального эффекта воздействия на потребителя. К примеру, проведение какого-то знакового события в рамках событийного маркетинга сопровождается поддержкой в прессе, по телевидению и радио; проведение конкурса в социальных сетях предполагает последующее награждение победителя на мероприятии. 


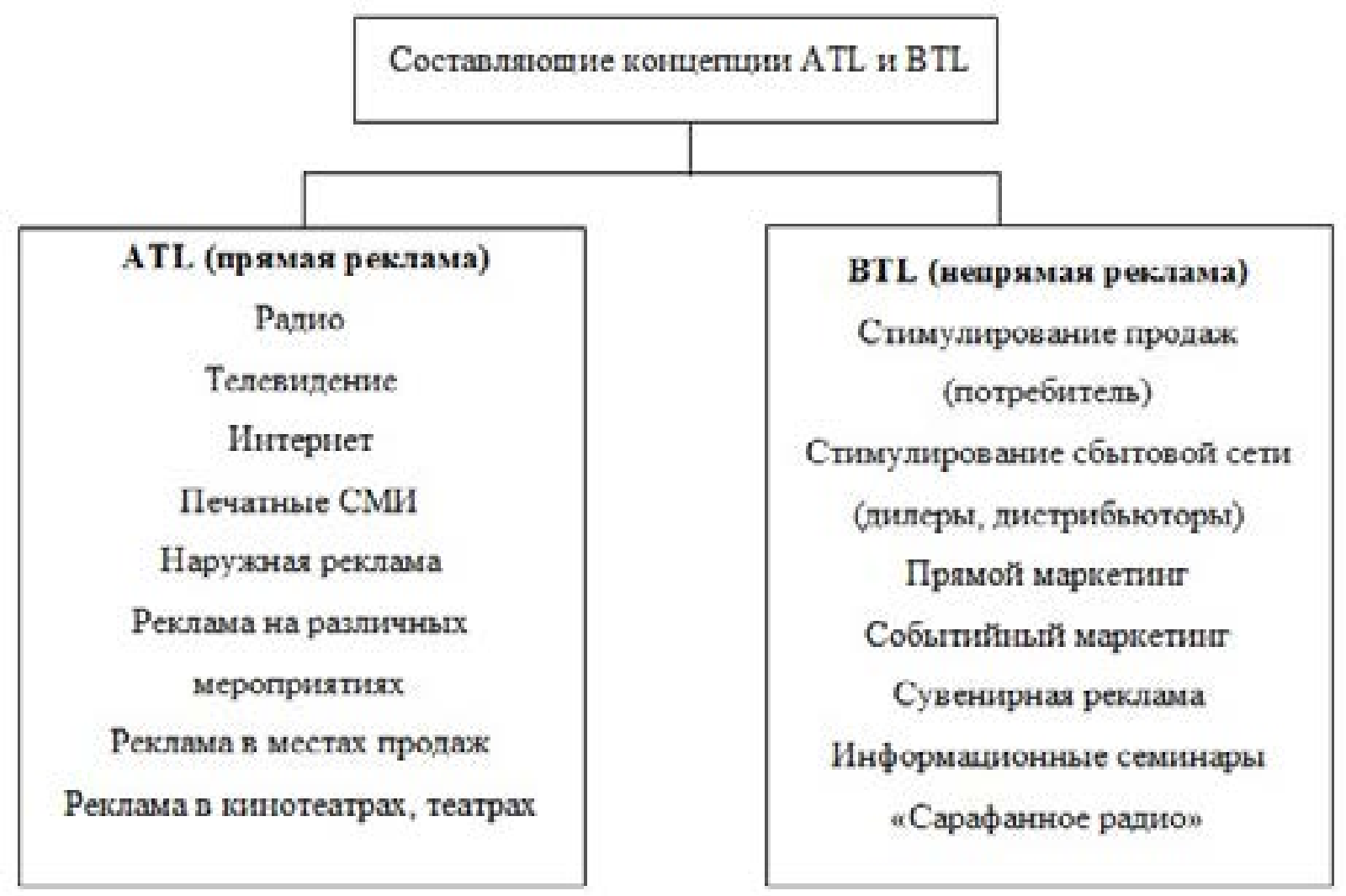

Рисунок 1. Технологии ATL и BTL. этапов:

Стратегия разработки коммуникационного сообщения состоит из двух

- разработка коммуникационного сообщения (формулировка идеи, определение наиболее подходящей мотивации и направления убеждения, выбор варианта размещения послания);

— организация медиапланирования для эффективного охвата целевой аудитории.

Кроме того, следует выделить два основных типа коммуникационных стратегий. Они отличаются тем, на чем основано сообщение; на реальных утилитарных свойствах продукта или на его психологически значимых свойствах. Данные стратегии предполагают использование разных каналы связи в качестве основных. В первом случае преобладает словесная информация, а во втором - невербальная информация (изображения, музыка, эффекты шоу и т. д.).

Выбор канала распространения для передачи необходимой информации целевой аудитории также обусловлен выбранными инструментами маркетинговых коммуникаций и имеющимися финансовыми ресурсами (к примеру, реклама по телевидению обойдется дороже, нежели реклама в социальных сетях). 


\section{СПИСОК ЛИТЕРАТУРЫ}

Бернет, Дж., Мориарти, С. (2015) Маркетинговые коммуникации: Интегрированный подход. СПб. : Питер. 864 с.

Зундэ, В. В. (2009) Концепция и алгоритмизированная модель формирования системы интегрированных маркетинговых коммуникаций российских компаний: дисс. ...канд. эконом. наук. Ростов н/Д. 450 с.

Коротков, А. В. (2019) Маркетинговые исследования: учебник. М.: Юрайт. 595 с.

Кравец, М. А. (2013) Коммуникативная стратегия: систематизация определений, подходы к разработке // Вестник Воронежского государственного университета. Сер. Экономика и управление. № 1. С. 149-153.

Лашкевич, Е. А. (2007) Маркетинговые стратегии формирования коммуникационной политики предприятий масс-медиа: на примере Липецкой области : дисс. ... канд. эконом. наук. Волгоград. 229 с.

Павлова, К. С., Ярмухаметова, С. А., Зотова, А. И. (2015) ATL- и BTL- Peклама в системе маркетинговых коммуникаций // Новое поколение. № 8. С. 311-314.

Рубанова, И. М., Фалина, И. В., Дьяконова, Т. В. (2012) Модернизационное маркетинговое управление коммуникациями и рекламными технологиями в вузе // Теория и практика сервиса: экономика, социальная сфера, технологии. № 4 (14). С. 263-267.

Симакина, М. А. (2019) Современные маркетинговые коммуникации: монография. М. : Издательство Московского гуманитарного университета.

Таран, А. В., Воблая, И. Н. (2017) Способы продвижения товаров: современные формы маркетинговых коммуникаций в России // Концепт. Т. 39. С. 561-2565.

Фридман, Л. (2018) Стратегия: Война, революция, бизнес / пер. с англ. И. Д. Голыбиной. М. : Кучково поле. 768 с.

Дата поступления: 20.12.2019 2.

Романюк Юлия Владимировна - магистрант факультета экономики, управления и международных отношений Московского гуманитарного университета. Адрес: 105318, Россия, г. Москва, ул. Юности, д. 5. Тел.: +7 (495) 787-87-67. Эл. адрес: IURomaniuk@synergy.ru

Romanyuk Yulia Vladimirovna, Graduate Student, Faculty of Economics, Management and International Relations, Moscow University for the Humanities. Postal address: 5, Yunosti St., Moscow, Russian Federation, 111395. Tel.: +7 (495) 787-87-67. E-mail: IURomaniuk@synergy.ru 


\section{Для цитирования:}

Романюк Ю. В. Методы формирования и реализации маркетинговых коммуникационных стратегий [Электронный ресурс] // Научные труды Московского гуманитарного университета. 2020. № 1. URL: http://journals.mosgu.ru/trudy/article/view/1127 (дата обращения: дд.мм.гг.). DOI: 10.17805/trudy.2020.1.8 